Further investigation of the we of apple luke as a reintorer for the shinchilla mat be useful. The pronounced preference for apple juice over water indicates its potential use as a reinforeer in experiments involving licking with the shinchilla.

\section{REFERENCES}

Corbit. J. D.. \& Luschei. E. S. Invariance of the rat's rate of drinking. Journal of Comparative \& Physiological Psychology. 1969. 69. 119-125.

Erber. N. P.. \& Beeler. A. Preferences of the chinchilla. Unpublished progress report of the Central Institute for the Deaf. No. 9.1966.
Stellar. E. \& Hill, J. H. The rat's rate of drinking as a function of water deprivation. Journal of Comparative \& Phrsiological Psychology. 1952. 45. 96-102

Thompson. $R$. The water consumption and drinking habits of a few species and strains of laboratory animals. Journal of the Institute of Animal Technicians, 1971,22, 29-36.

Van Twyer. H. Sleep patterns of five rodent species. Physiology \&. Behavior, 1969, 4, 901-905.

(Received for publication July 5. 1973.)

\title{
Discrimination learning and behavioral contrast as a function of component duration*
}

\author{
JAMES F. DICKSON. JR. and TERRY E. ZLEHLKE $\div$ \\ Saint Olat College. Vorthfield. Vinn. 5505 ?
}

Following 10 sessions of keypeck training on a VI $120-\mathrm{sec}$ reinforcement schedule, 24 pigeons were placed into one of three groups for subsequent discrimination training on a multiple VI-EXT schedule. The discriminative stimuli (two hues) alternated every $10 \mathrm{sec}(10-\mathrm{sec}$ group) or every $3 \mathrm{~min}$ (3-min group) during each $30-\mathrm{min}$ session. The third group received one $15 \cdot \mathrm{min}$ exposure of $\mathrm{S}+$ and one $15 \cdot \mathrm{min}$ exposure of $\mathrm{S}-$ per session (15-min group). Discrimination performance of these groups was best for the 10-sec group and worst for the 15-min group. The 10-sec group demonstrated higher $\mathrm{S}+$ rates, while the 15 -min group had the highest $\mathrm{S}-$ response rates.

Many details of discrimination training procedures have been shown to influence operant discriminative performance. For example. if Ss are first trained to respond to either a variable-interval (VI) or a multiple VI.VI schedule of reinforcement. subsequent discrimination training on a multiple VI-EXT schedule commonly results in an enhancement of response rates to St correlated with the extinction of responding to S-. Reynolds (1961) and Terrace (1963) have termed

*This investigation was supported by National Science Foundation College Science Improvement Program Grant GY-6887. Requests for reprints should be sent to James $F$. Dickson. Jr. Department of Psychology. St. Olaf College. Vickson. Jr.. Departmeld. Minn. 55057 .

TPresent address: Department of Psychology. University of
The South Dakota. Vermillion. S. Dak. this phenomenon "behavioral contrast." However, there are limits to the generality of behavioral contrast in multiple VI-EXT schedules. For example. when conditions are arranged such that the increase in response rate to the VI component is made at the cost of a reduction in reinforcement frequency in that component (as in tandem VI-DRL schedules). behavioral contrast is severely attenuated (Yarczower. Dickson. \& Gollub. 1968).

The present experiment was designed to investigate another manipulation of training conditions which might influence the properties of discriminative performance. the temporal duration associated with exposure to the reinforcement schedules and related stimuli. Typically. the schedules have been alternated or randomized. using fixed stimulus exposure periods of $3 \mathrm{~min}$. Bloomfield (1967) conducted a study in which the VI and EXT components of a multiple schedule were alternated on a session basis. That is. only one component was presented in any one daily session. Although behavioral contrast was still found. the magnitude of the effect was considerably attenuated. Hore recently. Shimp \& Wheatley (1971) and Todoror (1972) have employed multiple VI-VI schedules which differed in reinforcemen: density. and found that. as the durations of the schedule components were increased in length. the different rates controlled b! the two VI schedules tended to converge. Thus. in all three studies. the enhanced rates normally associated with the denser 


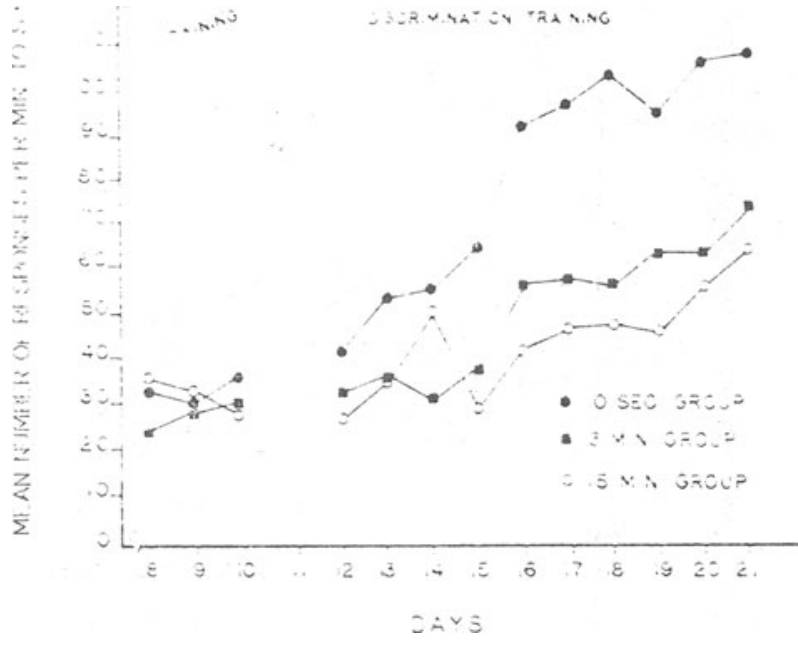

Fig. 1. Group mean response rates to S+ during Sessions 8-21.

reinforcement schedule decreased as component durations increased.

The present experiment exployed a stimulus alternation procedure similar to that used by Todorov and Shimp and Wheatley. but used multiple VI-EXT schedules of reinforcement. It was expected that the divergence of $\mathrm{S}+$ and $\mathrm{S}$ - response rates typical of behavioral contrast would be attenuated in multiple VI-EXT schedules in which components alternated relatively less often (i.e.. in which longer component durations were programmed).

\section{METHOD}

Subjects

Twenty-four experimentally naive homing pigeons obtained from a local supplier were individually housed with free access to food and water for several days following arrival at the laboratory. The Ss were then deprived of food and maintained at 75 ' of their free-feeding weights for the duration of the experiment. Water was always available in the home cages.

A Lehigh Valley piga test hamh:r ilodel 132-02) was used. The experimental imali were provited br an It 1 (Model 10-3043-1815-L) display (ell. and consisted of illumination of Kodak Wratten filters Yo. 99 (peak transmittance at $\$ 55 \mathrm{~nm}$ ) and So. 73 peak transmittance at $576 \mathrm{~nm}$ ). Houselights illuminated the experimental chamber for the duration of each experimental session. Contingencies were programmed and data were recorded by $28-1$ electromechanical relay equipment and counters.

\section{Procedure}

All Ss received identical pretraining. Throughout pretraining and baseline training. the stimulus on the response key was $555 \mathrm{~nm}$. Which subsequently became $\mathrm{S}+$ in discrimination training. Magazine training and keypeck shaping were accomplished on the first dat of training. S, received 50 continuous reinforcements for keypecking on the second session. The third day of pretraining consisted of a 30 -min exposure to a variable-interval $\mathrm{NI}$ hol-ee whedule of reinforcement. All $\mathrm{VI}$ interreinforcement interval, were generated according to the progression provided h! l lehler \& Hoffman 1962). Operant baselines were established over 10 vbequent $30-\mathrm{min}$ dail?

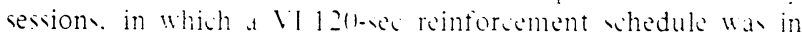

effect. In the next wion. a wavelength generalization test was given in extinctior. As the results of this generalization test are not relevant to the present experiment. they will not be considered further. (in the day following the generalization test. discrimination training was begun. With $\mathrm{S}$ s divided into three groups $(\mathbb{N}=8)$ matched on the basis of mean response rate during the last three VI sessions. For one group 110-sec group) 10-sec exposures of $\mathrm{S}+$ aiternated (i.e.. AB. AB ...) with 10 -sec exposures of $\mathrm{S}-$ (EXT). The second group (3-min group) received alternating 3 -min exposures of $S_{+}$and $S-$. while the third group (15-min group) received one 15 -min exposure of $\mathrm{S}+$ and one 15-min exposure of $\mathrm{S}-$ in each session. The schedule of reinforcement in effect during $\mathrm{S}+$ was VI 120 sec. A Gellerman series was used to determine the initial stumulus for each discrimination training session. Thus. all groups received equal total amounts of exposure to $S+$ and $S-$ in each session. with the important treatment variable being the duration of the individual schedule components.

\section{RESULTS AND DISCUSSION}

Overall performances of the three groups were initially summarized in a single discrimination index (DI). which indicates the percent of total responding made in the presence of $\mathrm{S}+$. With equal response rates in $\mathrm{S}+$ and $\mathrm{S}-$. the DI value would be 50 . This index thus allows for evaluation of the efficiency of discriminative performance for the three groups. The average discrimination index value for the 10-sec group was 75 : for the 3-min group. it was 66: and for the $15-\mathrm{min}$ group. it was 58. These data were analyzed by a Groups by Sessions analysis of variance. Component duration significantly affected overall discrimination performance $[F(2.21)=6.25 . p<.01]$. There was a significant improvement in discrimination performance for all Ss $[F(9.18)=18.60 . p<.01]$. and the change in discrimination performance across the 10 sessions differed for the three groups of Ss. producing a significant interaction between group and session: $[F(18.189)=1.75 \cdot p<.01]$. Thus, at least with the schedule component durations used in the present study. discrimination performance improves with shorter multiple schedule component durations.

Observed differences in group discriminative performances could be due to either (or both) of two causes: differences in performance in the presence of $\mathrm{S}+$ or differences in performance in the presence of $S-$. Separate analyses of group S+ and $\mathrm{S}$ - rates across sessions were therefore carried out.

Group mean response rates to $\mathrm{S}+$ across the last 3 sessions of single stimulus pretraining and the 10 sessions of discrimination training are depicted in Fig. 1. During discrimination training (Sessions 12-21). there was an overall increase in rate of St responding $[F(9.189)=$ 20.29. $\mathrm{p}<.011$. While the overall group differences in mean response rate to $\mathrm{S}+$ were not statistically. significant $[F(2.21)=1.94 . p>.05]$. the three groups differed in the rate at which $\mathrm{S}+$ responding increased across the experimental sessions. i.e.. the interaition between group and sessions is significant $[F(18.189)=$ 2.39. $p<.01]$. The groups clearly differed in $\mathrm{S}+$ response rates at the end of discrimination training. 
During the last three discrimination training sessions. the 10-sec group responded to $\mathrm{S}+$ at an average level approximately 3.05 times greater than during Sessions 8-10, while for the 3-min group, the corresponding ratio was 2.42 , and for the 15-min group, 1.68. These differences in $\mathrm{S}+$ rates between the experimental groups are ordered in a manner consistent with expectations based on the Todorov (1972) and Shimp \& Wheatley (1971) experiments, i.e., an attenuated $\mathrm{S}+$ response rate increase in the group exposed to longer schedule component durations.

Group mean response rates to $\mathrm{S}$ - during the discrimination training sessions are shown in Fig. 2. Overall amount of responding to $\mathrm{S}$ - did not differ for the three groups, $[F(2,21)=0.46, p>.05]$. Also, there was no overall decrease in level of responding to $\mathrm{S}$ $[F(9.189)=1.40, p>.05]$. However, the three groups differed in changes in response rate to $S-$ across the 10 sessions of Phase $2[F(18,189)=2.39, p<.01]$, i.e., the Groups by Sessions interaction is significant. This significant effect, as well as the considerable overlap in the $10-\mathrm{sec}$ and the 3-min group functions, suggests that the $\mathrm{S}$ - responding of the 15 -min group during these discrimination sessions was quite different from that of either the $10-\mathrm{sec}$ or $3-\mathrm{min}$ groups. Inspection of the $\mathrm{S}-$ rate functions indicates that, if anything, responding to $\mathrm{S}$ - was increasing somewhat for the 15-min birds, while for the other two groups, a slight decrease was suggested. Thus, it appears that different rates of schedule alternation in the multiple VI-EXT schedule will be correlated with different rates of extinction of responding in the presence of $\mathrm{S}-$. The failure of the three groups to show a measurable reduction in $\mathrm{S}$ responding is probably due to the extensive amount of single-stimulus pretraining administered prior to the introduction of the multiple schedule. Several experiments recently performed in Thomas's laboratory ${ }^{1}$ have replicated this finding.

The present study demonstrates that component duration merits closer investigation as a variable affecting the development of discriminative performance in successive operant discriminations. This study has demonstrated a result similar to that of Shimp \& Wheatley (1971), i.e., convergence of response rates with infrequent schedule alterations. In the present experiment, this finding has been extended from multiple VI-VI to multiple VI-EXT schedules. The finding of less contrast (i.e., an increase in VI response rates following single-stimulus pretraining and subsequent exposure to a VI-EXT multiple schedule) with longer durations probably has as a limiting case exposure to only the VI component of the multiple VI-EXT schedule. What is the limit to increases in behavioral contrast as components alternate more and more rapidly? Todorov (1972) has suggested that for a given pair of unequal multiple VI-VI schedules, the relative rate associated with the richer schedule increases as the rate of changeover increases up to a point when

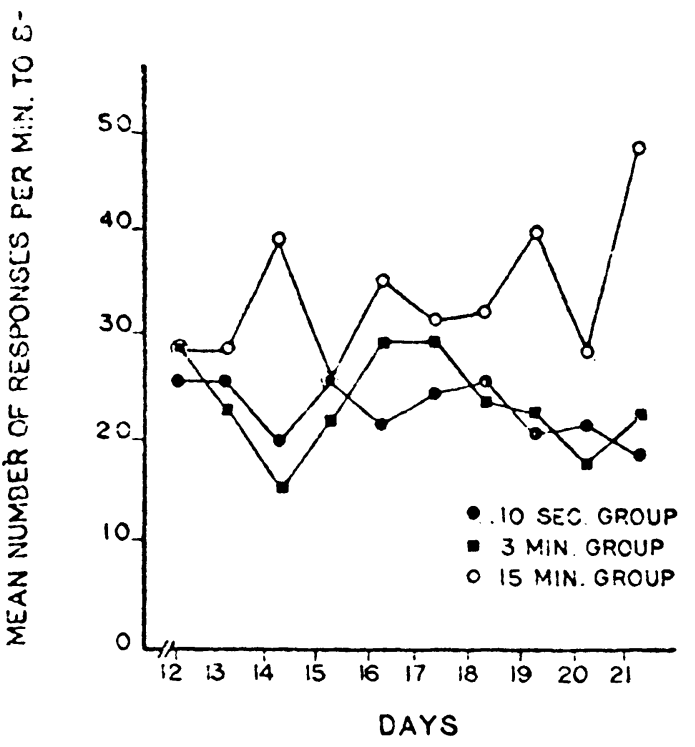

Fig. 2. Group mean response rates to $S$ - during discrimination training sessions.

component durations are so short that an alternation of responses to the two components occurs. Comparably short durations, in the case of VI-EXT, would be analogous to exposure to a single VI schedule with a density of reinforcement one-half of that programmed in the multiple schedule. As it is known that VI reinforcement schedules in which fewer reinforcements are programmed are generally associated with lower rates of response, "contrast," as defined in this paper, might be expected to eventually decrease as component alternations became exceedingly rapid. This interpretation is consistent with Todorov's (1972) finding of an increase in relative response rate to the richer schedule of a multiple VI-VI pair as component durations are shortened, with a subsequent decrease as component durations became excessively short.

\section{REFERENCES}

Bloomfield, T. M. Some temporal properties of behavioral contrast. Journal of the Experimental Analysis of Behavior, $1967,10,159-164$.

Fleshler, M., \& Hoffman, H. S. A progression for generating variable-interval schedules. Journal of the Experimental Analysis of Behavior, $1962,4,529-530$.

Reynolds, G. S. Behavioral contrast. Journal of the Experimental Analysis of Behavior, 1961, 4, 57-71.

Shimp, C. P., \& Wheatley, K. L. Matching to relative reinforcement frequency in multiple schedules with a short component duration. Journal of the Experimental Analysis of Behavior, 1971, 15, 205-210.

Terrace, $H$. S. Discrimination learning with and without "errors." Journal of the Experimental Analysis of Behavior, 1963, 6, 1-27.

Todorov, J. C. Component duration and relative response rate in multiple schedules. Journal of the Experimental Analysis of Behavior, 1972, 17, 45-49.

Yarczower, M., Dickson, J. F., \& Gollub, L. R. Some effects on generalization gradients of tandem schedules. Journal of the Experimental Analysis of Behavior, 1968, 9, 631-639.

\section{NOTE}

1. David R. Thomas, personal communication, 1973. We wish to thank Dr. Thomas for a critical reading of this manuscript.

(Received for publication July 20. 1973.) 